This item was submitted to Loughborough's Research Repository by the author.

Items in Figshare are protected by copyright, with all rights reserved, unless otherwise indicated.

\title{
Ultra-high performance fibre-reinforced cementitious composite with steel microfibres functionalized with silane
}

PLEASE CITE THE PUBLISHED VERSION

https://doi.org/10.1016/j.conbuildmat.2018.05.167

\section{PUBLISHER}

(C) Elsevier

VERSION

AM (Accepted Manuscript)

\section{PUBLISHER STATEMENT}

This work is made available according to the conditions of the Creative Commons Attribution-NonCommercialNoDerivatives 4.0 International (CC BY-NC-ND 4.0) licence. Full details of this licence are available at: https://creativecommons.org/licenses/by-nc-nd/4.0/

\section{LICENCE}

CC BY-NC-ND 4.0

\section{REPOSITORY RECORD}

Casagrande, Cezar Augusto, Sergio H. Cavalaro, and Wellington Longuini Repette. 2019. "Ultra-high Performance Fibre-reinforced Cementitious Composite with Steel Microfibres Functionalized with Silane". figshare. https://hdl.handle.net/2134/34577. 
$6 \quad{ }^{1}$ Department of Civil Engineering (ECV), Federal University of Santa Catarina (UFSC), João Pio

7 Duarte Silva s/n, Córrego Grande, CEP 88040-900 Florianópolis, Santa Catarina, Brazil

8

$9{ }^{2}$ School of Architecture, Building and Civil Engineering, Loughborough University

10 Leicestershire, LE11 3TU, UK.

11

\section{ULTRA-HIGH PERFORMANCE FIBRE-REINFORCED CEMENTITIOUS COMPOSITE WITH} STEEL MICROFIBRES FUNCTIONALIZED WITH SILANE

Cézar Augusto Casagrande ${ }^{1 *}$; Sergio Henrique Pialarissi Cavalaro²; Wellington Longuini Repette ${ }^{1}$.

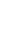

1

*Corresponding author: cezar.acasa@gmail.com (C.A. Casagrande).

3

\section{HIGHLIGHTS:}

- $\quad$ Silane film of TEOS is formed over the fibre after functionalization;

- Increase of silane content in functionalization leads to higher pullout bond strength;

- $\quad$ Functionalization with TEOS enhance fibre-matrix interfacial properties;

- The Si/Ca ratio in the fibre-matrix interface is increased when the TEOS functionalization is applied;

\section{0}

\section{ABSTRACT}

This paper explores the effect of fibre functionalization with tetraethoxysilane (TEOS) in the microstructure and mechanical property of ultra-high performance cement composites with steel fibres. Fibres treated with three concentrations of TEOS were evaluated by pullout tests and SEM/EDS analysis. Mixes with treated fibres showed up to $35.6 \%$ increase in bond strength and up to $49.5 \%$ reduction in the crack opening at the peak pullout load in comparison with 
27 reference mixes containing untreated fibres. The Si/Ca ratios in the fibre-matrix transition zone

28 increases with the increment of the concentration of TEOS in the treatment of the fibre. This

29 indicates an increase of $\mathrm{C}-\mathrm{S}-\mathrm{H}$ at the interface that justifies the enhanced mechanical 30 performance.

31 KEYWORDS: Silane, fibre pullout, functionalization, interface adhesion, UHPFRC.

331 INTRODUCTION

Introduced in the 80's, Ultra-High Performance Fibre Reinforced Concrete (UHPFRC) [1,2] has very high compressive strength (more than $150 \mathrm{MPa}$ at 28 days [3,4]) and enhanced durability [5]. This is achieved by combining high content of binders, low water-to-binder ratios

37 (typically smaller than 0.20 by weight) and ultrafine mineral admixtures. In most structural applications, mixes incorporate straight metallic microfibres to compensate for the brittle behaviour of the cementitious matrix and to achieve higher ductility and toughness in tension $40 \quad[6,7]$.

Pullout tests of UHPFRC, performed in specimens with aligned straight steel fibres embedded in cementitious concrete matrix, reveal a three-stage mechanical response [8-11].

43 An elastic stage takes place for small displacements as fibre and matrix show compatible deformation and the integrity of the fibre-matrix interface is maintained. As the load increases, tangential stresses in the fibre-matrix interface induce micro-cracks along the length of the fibre, initiating the debonding stage. Once the tangential stress reaches the bond strength along a

47 critical length, the integrity of the interface is fully compromised and the strain compatibility 48 between fibre and matrix cease to exist. The sliding stage follows, characterized by the relative 49 displacement between fibre and matrix. The restriction to this movement is the result of friction 50 at the fibre-matrix interface.

51 Since the tensile failure of UHPFRC is governed by the bond between fibre and matrix, 52 attempts to enhance the mechanical performance of the material in tension often focus on 
53 improving the interfacial properties through modifications of the matrix composition or of the

54 fibre geometry [12-14]. Few studies have addressed this issue by means of surface treatments 55 applied to the surface of metallic fibres, prior to their mixing with concrete.

In several industrial applications, silane films are used as surface coatings to improve corrosion resistance $[15,16]$ and as a primer to improve the adhesion of other polymeric coatings to metal plates $[17,18]$. Silanes are molecules of general formula $\mathrm{R}_{y}^{\prime}\left(\mathrm{CH}_{2}\right)_{n} \mathrm{Si}(\mathrm{OR})_{4-y}$, in which $\mathrm{R}^{\prime}$ is an organofunctional group and R is a hydrolysable alkoxy group [19]. Studies with silane coupling agents showed the possibility of producing sheets of hybrid calcium silicate hydrate from the reaction of hydrolysed silanes in calcium hydroxide solution at room temperature [20-22]. Other studies revealed the potential use of silanes to improve properties in cement-based materials, such as workability or durability [23-28].

Research on modification of fibre surface with silanes to improve the performance of interfaces with cement-based matrices is still limited. [29] and [30] evaluated the mechanical properties of non-metallic fibres treated with silane and embedded in conventional cement matrixes. Pullout tests indicated an increase of up to $150 \%$ in the average bond strength and of up to $300 \%$ in the toughness. Similarly, [31] performed surface modification of polymeric fibres with silane for reinforcement of concrete. The authors found that the increase of mechanical properties resulted from the formation of high amount of calcium silicates hydrates (C-S-H) at the surface of the fibre. metallic fibres in UHPFRC is still unexplored. The objective of this study is to investigate the influence of steel fibres functionalization with silane on the pullout behaviour and on the characteristics of the fibre-matrix interface in UHPFRC. 


\section{EXPERIMENTAL PROGRAM}

\subsection{FIBRE TREATMENT}

Brass covered straight steel microfibre, with $13 \mathrm{~mm}$ of length, $0.16 \mathrm{~mm}$ of diameter and

tensile strength of $2000 \mathrm{MPa}$ was used in this study. This fibre has been extensively used in

UHPFRC. The surface treatment used tetraethoxysilane $\left(\mathrm{C}_{8} \mathrm{H}_{20} \mathrm{O}_{4} \mathrm{Si}\right)-\mathrm{a}$ silane also known as TEOS

with purity higher than $98 \%$ and specific gravity of $0.9935 \mathrm{~g} / \mathrm{cm}^{3}$. TEOS is among the most

commonly used silanes in industrial functionalization of metals due to its controllable hydrolysis

velocity and high degree of crosslink [32].

to release hydroxyls radicals (silanol) able to react with the base surfaces (metallic surface, in purity higher than 96\%) in water was used to disperse the silane. Then, acetic acid was added to ensure a solution with $\mathrm{pH}$ of $5 \pm 0.2$. After that, the solution was constantly homogenized in a magnetic stirrer at $25^{\circ} \mathrm{C}$. The optimum hydrolysis time was determined by infrared analysis (FTthe $\mathrm{Si}-\mathrm{OH}$ (silanol) formation. Lower index at $960 \mathrm{~cm}^{-1}$ bands indicates a larger concentration of of hydrolysis.

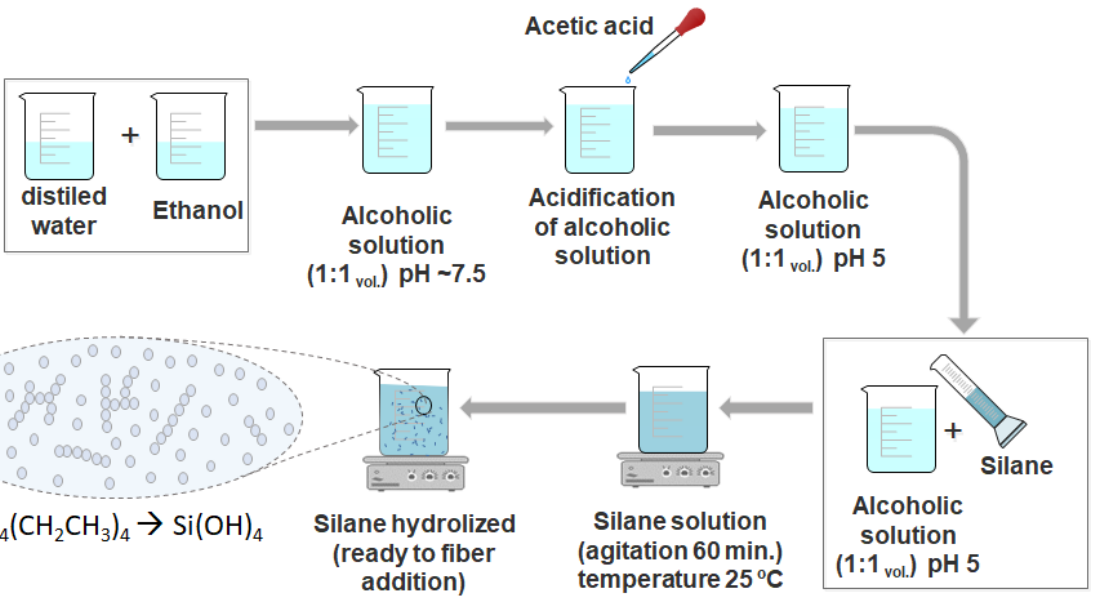

Fig. 1 - Representation of the TEOS hydrolysis procedures 
99 of metallic plates with amino, ureido and epoxysilanes [35-37]. For the functionalization of

100 synthetic fibres, [29] and [30] used concentrations of $0.5 \%, 0.75 \%$ and $1.0 \%$ by volume of

101 vinylsilane. Based on that, solutions with $0.1 \%, 0.5 \%$ and $1.0 \%$ of TEOS by volume were prepared

102 in the present study ( $T \_0.1 \%, T \_0.5 \%$ and $T \_1.0 \%$, respectively).

103 Fig. 2 summarizes the steps for the functionalization of the steel fibres, which was adapted

104 from the work by [33]. Fibres were first submerged during 2 minutes in 1:0.25 solution of 105 acetone $\left(\mathrm{C}_{3} \mathrm{H}_{6} \mathrm{O}\right.$ with purity higher than $\left.96 \%\right)$ in water to remove dust or grease off their surface 106 and, then, dried during 12 hours in a ventilated oven at $100^{\circ} \mathrm{C}$.

107

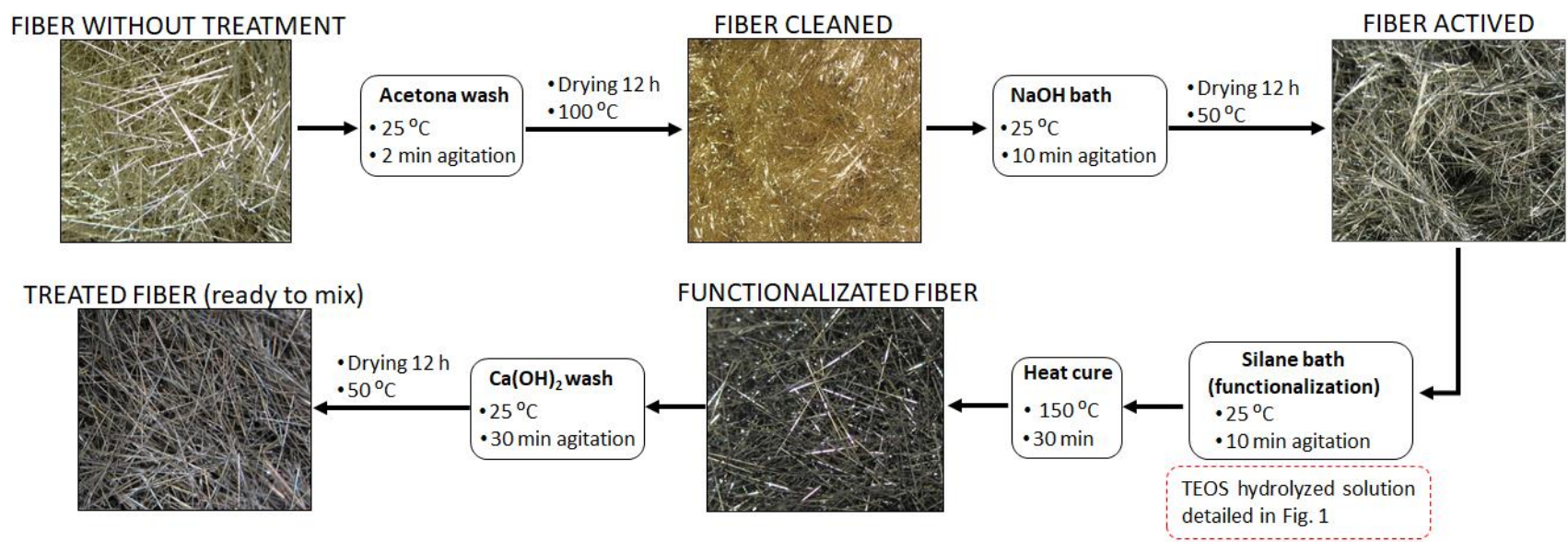

109

Fig. 2 - Steps of fibre surface treatment

110

111 Next, the surface of the fibres was activated by the deposition of hydroxyl groups $\left(\mathrm{OH}^{-}\right)$

112 that might react with TEOS. Fibres were submerged in a $0.625 \mathrm{M}$ aqueous solution of $\mathrm{NaOH}(97 \%$

113 purity) at $25^{\circ} \mathrm{C}$ under constant agitation for $10 \mathrm{~min}$, rinsed with distilled water and dried in an

114 oven at $50{ }^{\circ} \mathrm{C}$ for 12 hours. At this stage of the process, the surface of the fibres composed of a

115 thin layer of brass oxidizes superficially, resulting in a darker finishing. This surface oxidation

116 does not damage the steel of the fibre or affect the efficiency of the functionalization process.

117 After that, the functionalization of the surface with TEOS was conducted following a sol-gel dip

118 coating process. Fibres were submerged in the solution with the hydrolysed TEOS produced 
119 according with Fig. 1, in a proportion of $300 \mathrm{~g} / \mathrm{L}$. The components were constantly agitated in a

120 mechanical stirrer during $10 \mathrm{~min}$ at $25^{\circ} \mathrm{C}$, rinsed in distilled water and cured for $30 \mathrm{~min}$ in an 121 oven at $150^{\circ} \mathrm{C}$.

122 Fibres were then submerged in a $0.1 \mathrm{M}$ aqueous solution of $\mathrm{Ca}(\mathrm{OH})_{2}$ (purity higher than $12395 \%$ ), which was agitated for $30 \mathrm{~min}$ at $25^{\circ} \mathrm{C}$ to remove loose TEOS from the surface. The removal

124 of loose TEOS film prevented undesirable change in the composition of UHPFRC and a 125 retardation of the cement setting observed in the presence of loose TEOS film during a 126 preliminary stage of the experimental program. Finally, fibres were rinsed in distilled water and 127 oven dried at $50^{\circ} \mathrm{C}$ for $12 \mathrm{~h}$.

128

\subsection{PREPARATION OF THE COMPOSITE SPECIMENS}

130 An initial experimental campaign was conducted to adjust the mix and to assure the 131 desired performance in fresh and hardened states. Table 1 shows the materials and the 132 composition defined used to produce the UHPFRC (defined in accordance with previous studies 133 by [38-40]).

Table 1 - Components and mix composition of UHPFRC

\begin{tabular}{lcccc}
\hline Materials & Density & $\begin{array}{c}\text { Proportion } \\
\text { by weight }\end{array}$ & $\mathbf{k g} / \mathbf{m}^{\mathbf{3}}$ & $\begin{array}{c}\text { Apparent } \\
\text { volume (\%) }\end{array}$ \\
\hline Cement CEM I 52.5R & 3.11 & 1.00 & 939.8 & 30.21 \\
Fine Sand & 2.64 & 1.21 & 1140.3 & 43.19 \\
CaCO $_{3}$ powder & 2.70 & 0.11 & 103.4 & 3.82 \\
Superplasticizer & 1.05 & 0.07 & 66.2 & 6.30 \\
Nano-silica & 1.13 & 0.07 & 67.2 & 5.92 \\
Mixing water & 1.00 & 0.09 & 85.8 & 8.58 \\
Fibres (untreated) & 7.95 & 0.16 & 155.1 & 2.00 \\
\hline
\end{tabular}

137 The Cement CEM I 52.5R followed the specifications of EN 197-1 [41]. The silica sand had $13899.5 \%$ of $\mathrm{SiO}_{2}$, a maximum nominal particle size of $0.6 \mathrm{~mm}$ and an average particle size of 0.3

$139 \mathrm{~mm} . \mathrm{CaCO}_{3}$ powder with average particle size of $3.9 \mu \mathrm{m}$ was used as filler. Nano-silica, in 140 suspension with a solid content of $22 \%$ and average particle size of $99.35 \mathrm{~nm}$, was also used. The 
141 superplasticizer was a sodium polycarboxylate with a solid content of $25 \%$. The effective water-

142 to-cement ratio (considering the water provided by the components) was approximately 0.20 .

143 UHPFRC with the composition from Table 1 had an average flow of $191 \mathrm{~mm}$ in accordance with

144 ASTM C1437 [42]. The average compressive strength at 28 days according to the EN 196-1 [43]

145 was $172.4 \mathrm{MPa}$, with a standard deviation of 6.7 MPa.

146 All mixes were produced with $2 \%$ by volume of fibres treated with the silane

147 concentrations described in previous sections (T_0.1\%, T_0.5\%, and T_1.0\%). For comparative

148 purposes, reference mixes with untreated fibres (REF) were also produced.

149 A mixer model with a vertical axis was used. First, all solid materials were homogenized

150 for $3 \mathrm{~min}$. Then, the liquids were added in the following order separated from each other by 1

151 min of mixing: all nano-silica, $50 \%$ of the water, $90 \%$ of superplasticizer and the remaining

152 liquids. After mixing for $5 \mathrm{~min}$, fibres were slowly added during $5 \mathrm{~min}$. Finally, the UHPFRC was

153 mixed for 5 min more.

154 Then, specimens were cast for the pullout test of multiple fibres, similarly to the described

155 in [10], [14] and [44]. A thin polyethylene plastic sheet with dimensions $40 \times 40 \times 0.5 \mathrm{~mm}$ was

156 pierced with evenly spaced holes forming a 5 by 5 grid. Fibres were placed at half of their length,

157 perpendicularly to each hole (Fig. 3.a). The polyethylene sheet was, then, positioned at the

158 central part of a mould with internal dimensions of $40 \times 40 \times 80 \mathrm{~mm}$. This guaranteed a uniform

159 fibre distribution, their perpendicular alignment with the largest dimension of the specimen and

160 a preferential cracking plane during the pullout tests.

161 The UHPFRC was poured on both sides of the thin polyethylene sheet and compacted in

162 accordance with UNE-EN 196-1 [43]. Special care was taken to guarantee a complete filling of

163 the space between fibres, minimizing their displacement or spin. Specimens were demoulded

16424 hours of casting, remaining in a climatic chamber at $23^{\circ} \mathrm{C}$ and relative humidity higher than

$16599 \%$ for 28 days. Six specimens per series were produced. 


\subsection{PULL OUT TESTING PROCEDURE}

168 Fig. 3.b shows the setup of the pullout test conducted in a hydraulic press, using a load

169 cell with $5 \mathrm{kN}$ nominal capacity and $0.001 \mathrm{kN}$ resolution. Both ends of the specimens were glued

170 with an epoxy adhesive to the plates of the press. An extensometer was placed with the cracking

171 plane in the middle. Following [10], the test was conducted at a constant displacement rate of

$1720.3 \mathrm{~mm} / \mathrm{min}$ controlled by the extensometer. The pullout load $(P)$ was registered throughout the

173 test.

174

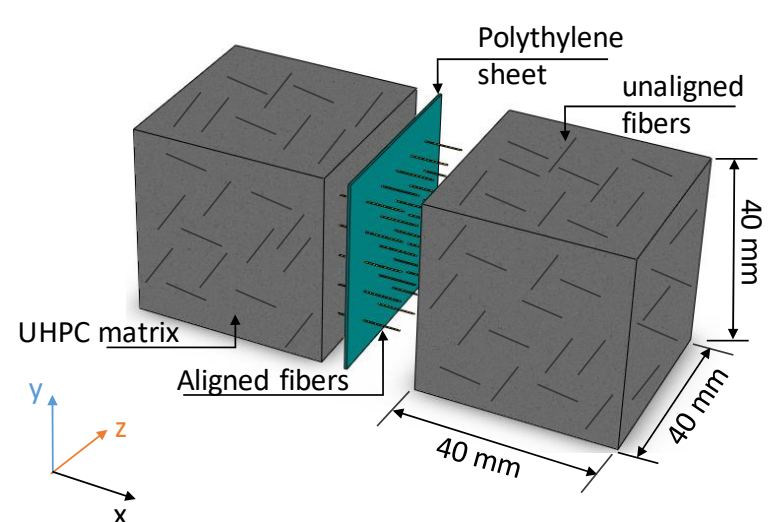

(a)

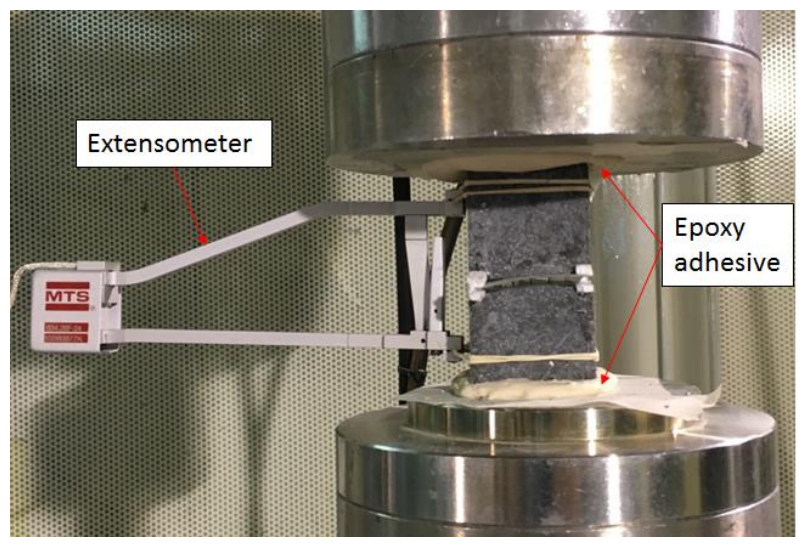

(b)

Fig. 3 - Pullout samples: detailed view of parts of the specimen (a) and pullout test setup (b) opening and the elastic deformation of the UHPFRC between the points of measurements. Due to the low load reached during the test and the high Young Modulus of the UHPFRC, the displacement induced by the elastic deformation is several orders of magnitude smaller than the sensitivity of the extensometer and may be disregarded. Therefore, the displacement is considered equal to the crack opening $(w)$. maximum pullout load, $n$ is the number of fibres in the cracked section, $d$ is the fibre diameter $(0.16 \mathrm{~mm})$ and $/$ is the embedded length at each side of the polypropylene sheet $(6.5 \mathrm{~mm})$. 
188 pullout, which was calculated with Eq. (2) through the integration of the area under the load-

189 crack opening curve. The pullout energy was estimated for crack openings of $0.5 \mathrm{~mm}\left(E_{0.5}\right)$ and

$1902.5 \mathrm{~mm}\left(E_{2.5}\right)$, associated to the serviceability limit state and ultimate serviceability limit state,

191 respectively [47]. Notice that such crack openings are usually defined for conventional fibre

192 reinforced concrete, not UHPFRC. In UHPFRC, a bigger number of cracks tend to appear due to

193 the hardening behaviour of the material. Consequently, a smaller crack opening is expected to

194 occur both in the ultimate limit state for the same strain level.

195

$$
\begin{gathered}
\tau_{\max }=\frac{P_{\max }}{n \cdot \pi \cdot d \cdot l} \\
E_{w}=\int_{0}^{w} P_{(w)} d w
\end{gathered}
$$

All parameters derived from the pullout test represent the average of 6 determinations per type of fibre. To identify changes induced by the treatment, the surfaces of the fibres were analysed before they were embedded in the UHPFRC matrix and after the pullout tests by means of Scanning Electron Microscopy with X-ray microanalysis (SEM/EDS). Furthermore, to evaluate the fibre-matrix interface, samples of $5 \times 5 \times 5 \mathrm{~mm}$ were cut out of the pullout specimens. These samples were dry-polished in a rotary polisher during $10 \mathrm{~min}$ at $1000 \mathrm{rpm}$ with a $3 \mu \mathrm{m}$ grain sandpaper and inspected by SEM/EDS. These analyses were performed in a microscope at the voltage of $15 \mathrm{kV}$ to obtain backscattered electron images.

\section{RESULTS AND ANALYSIS}

\subsection{PULLOUT BEHAVIOR}

Fig. 4 shows the average curves that relate the pullout load $(P)$ and the crack opening 
210 different concentrations of TEOS. All curves reveal a similar behaviour characterized by an initial

211 stage with a significant increase in $P$, with almost no increase in $w$.

212

213

214

215

216

217 of both $w$ and $P$. Although no clear trend related to the content of TEOS is identified, REF series

218 (untreated) debonding initiates at a load 31.7\% bigger than the average registered for series with

219 treated fibres. Despite that, the pullout load reached during the debonding stage in series with

220 treated fibres is up to $35.6 \%$ bigger than the observed in REF series. This suggests that the

221 functionalization with TEOS enhances the capability of the fibre-matrix interface to transmit

Fig. 4 - Pullout curves.

Debonding initiates for a pullout load around $200 \mathrm{~N}$, being characterized by an increase stresses before significant damage appears.

Once $w$ reaches approximately $0.04 \mathrm{~mm}$, debonding is completed and fibre slippage takes place. At this stage, the pullout load remains practically constant whereas $\mathrm{w}$ increases. From a certain point on, a decrease in $\mathrm{P}$ is observed as $\mathrm{w}$ increases and the embedded length of the fibres in the matrix is reduced. The decrease registered for the series with TEOS is proportionally bigger than the one verified for the REF series. The bigger load mobilized in the debonding stage of mixes with treated fibres due to a stronger fibre-matrix interface leads to a

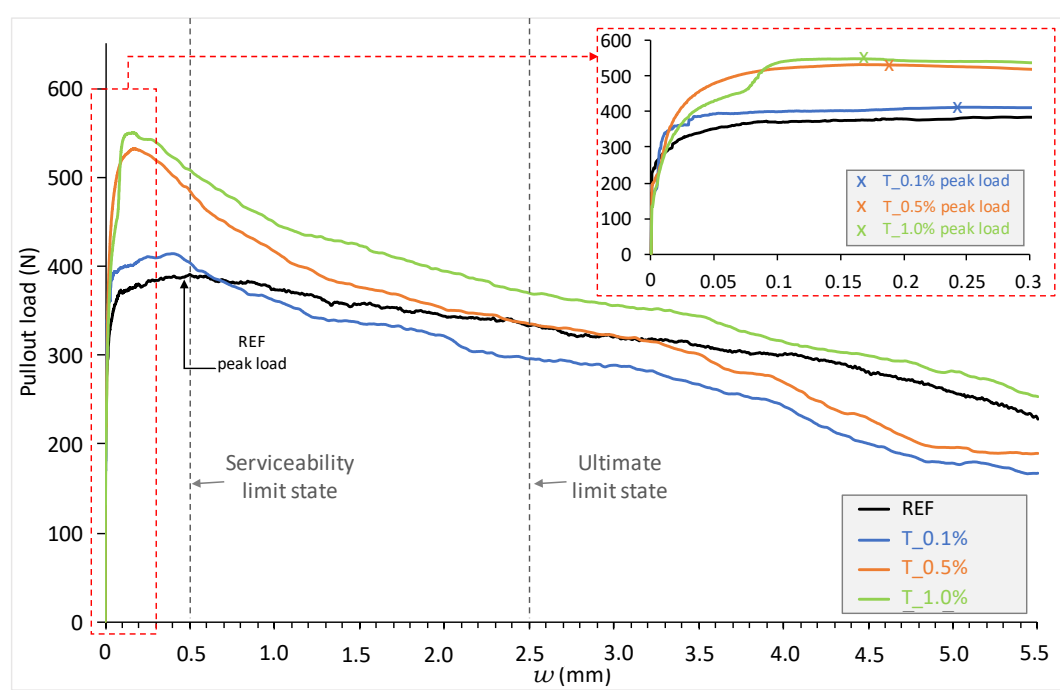


229 more pronounced loss of load capacity. As the interface is debilitated, the pullout load becomes

230 a consequence of frictional forces during the slipping stage.

231 Elements made with UHPFRC tend to present multiple cracking due to the strain

232 hardening behaviour of the material, which is consistent with the small fibre length normally

233 used. Crack openings of less than $1 \mathrm{~mm}$ are expected for both serviceability and ultimate limit

234 states. Therefore, if further statistical analysis confirms that the average differences observed in

235 Fig. 4.; UHPFRC made with treated fibres should outperform those made with reference

236 untreated fibres, since for small crack openings the latter presents higher pullout loads than the

237 former.

238

\subsection{BOND STRENGTH}

Fig. 5 in the principal axis shows the maximum bond strength $\left(\tau_{\max }\right)$ calculated from the

241 pullout test results according to Eq. 1. Fig. 5 in the secondary axis shows the average crack opening $\left(w_{p}\right)$ corresponding to $\tau_{\max }$. The error bars depict the confidence interval for a significance level of 0.05 . The coefficient of variation (CV) of the maximum bond strength and

244 the toughness remains between $8 \%$ and $10 \%$. The CV of the load increases with the crack opening, reaching values of $25 \%$ for a crack opening of $5.5 \%$. These results are consistent with

246 the findings by [10], [48] and [49]. The $\tau_{\max }$ of the untreated sample (REF) is comparable to

247 values found in previous studies [10,50], while the $\tau_{\max }$ of series treated with $0.1 \%, 0.5 \%$ and

$248 \quad 1.0 \%$ of TEOS were respectively $7.5 \%, 30.4 \%$, and $35.6 \%$ bigger on the average. 


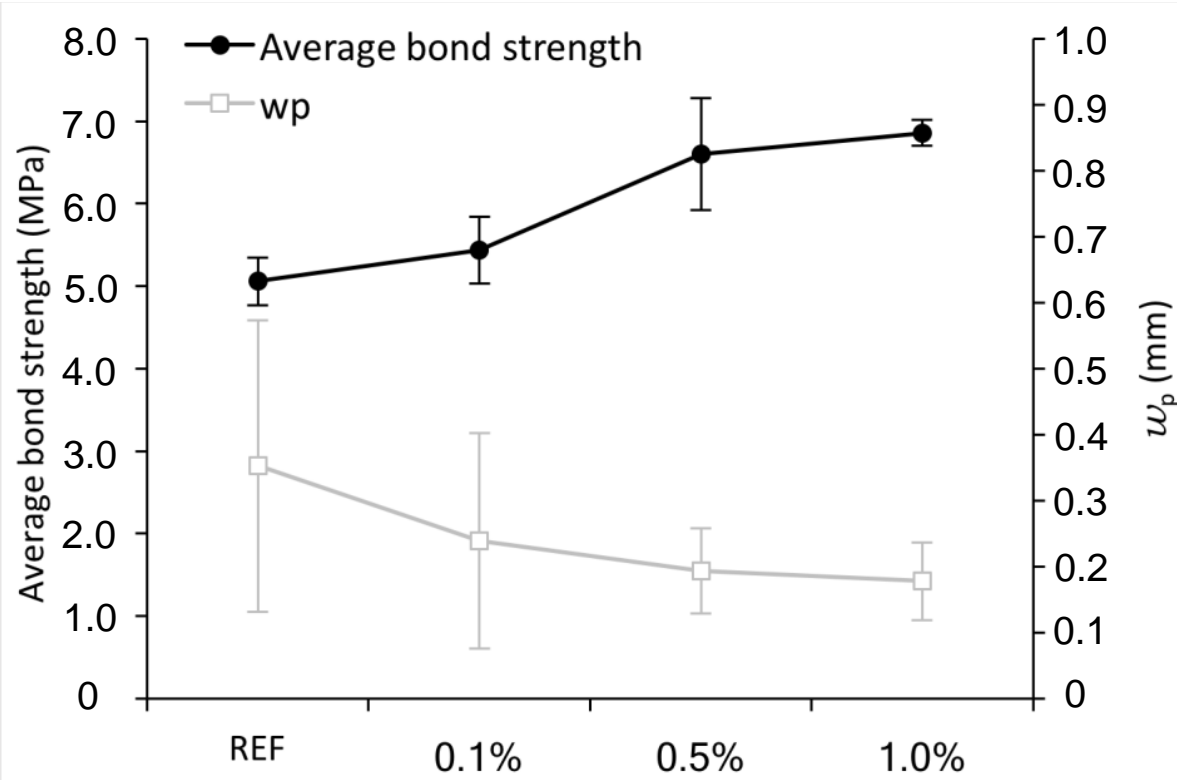

Fig. 5 - Effect of TEOS content in maximum bond strength and in the corresponding crack opening

A one-way ANOVA was conducted to compare the effect of the treatment on $\tau_{\max }$ and the Duncan's test was used to compare the means. The increase in $\tau_{\max }$ observed in treated samples in comparison with untreated ones is statistically significant $(F=14.47 ; p$-value $=0.00)$. This confirms that the fibre functionalization conducted in this study contributes to enhancing the strength of the fibre-matrix interface.

The post hoc comparison of REF series and series treated with $0.10 \%$ of TEOS indicates no significant difference. Conversely, the comparison between the REF series with series treated either with $0.5 \%$ of TEOS or with $1.0 \%$ of TEOS indicates statistically significant differences. These results reveal that a minimum content of TEOS is required to achieve improvement in the bond strength. Interestingly, no statistically significant difference was found in the comparison between series treated with $0.5 \%$ and $1.0 \%$ of TEOS. This suggests a saturation effect as no significant differences are observed despite doubling the TEOS concentration. Such observations are consistent with the study conducted by Benzerzour et al. [29] that observed optimal results for $0.5 \%$ of silane content in the treatment of unsaturated polyester/glass fibre.

A reduction in $w_{p}$ is observed in the series with treated fibres in comparison with that found in REF series, which becomes more evident as the content of TEOS in the treatment 
270 increases. In fact, series treated with $0.1 \%, 0.5 \%$ and $1.0 \%$ of TEOS show $w_{p} 32.3 \%, 45.0 \%$ and

$27149.6 \%$ smaller than that observed in REF series. This behaviour may arise from the formation of

272 a stiffer fibre-matrix interfacial zone that, despite being capable of transmitting higher loads,

273 loses the bearing capacity as damage appears in the interface and the pullout stress the slipping

274 stage governed by friction.

275

276

\subsection{PULLOUT ENERGY}

277

Fig. 6 shows the average pullout energy calculated with Eq. 2 for crack openings of 0.5 $\mathrm{mm}\left(E_{0.5}\right)$ and $2.5 \mathrm{~mm}\left(E_{2.5}\right)$. Series treated with $0.1 \%, 0.5 \%$ and $1.0 \%$ of TEOS show $7.2 \%, 33.9 \%$ and $36.2 \%$ bigger $E_{0.5}$ than the ones obtained in REF series. In terms of $E_{2.5}$, the series treated with $0.5 \%$ and $1.0 \%$ of TEOS remain higher than the REF series, although differences are reduced

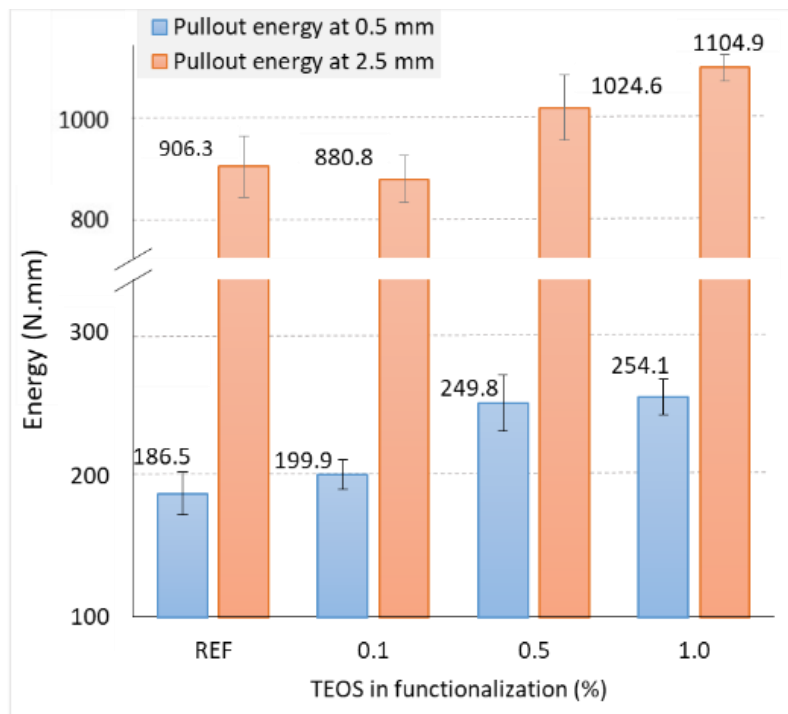

Fig. 6 - Accumulated pullout energy for $w_{p}$ of $0.5 \mathrm{~mm}$ and $2.5 \mathrm{~mm}$

The increase in accumulated pullout energy observed in treated samples in comparison with untreated ones is statistically significant $\left(\mathrm{F}=15.45\right.$ and $\mathrm{p}$-value $=.000$ for $w_{p}$ of $0.5 \mathrm{~mm}$; 
290 series with $0.1 \%$ of TEOS indicate no statistical differences for the crack openings analysed.

291 However, the pullout energy from both series are significantly different from the observed for

292 series treated with $0.5 \%$ and $1.0 \%$ of TEOS. The difference between series treated with $0.5 \%$ and

$2931.0 \%$ of TEOS is only statistically significant for $w_{p}$ of $2.5 \mathrm{~mm}$.

294 These results show that the functionalization of the fibre surface with silane can

295 effectively enhance the fracture toughness of UHPFRC. In the case of UHPFRC, this gain in pullout

296 energy tends to be proportionally bigger for low $w_{p}$ than for high $w_{p}$. As mentioned in section

2973.2 , a minimum silane content is required to achieve significant improvement in the pullout

298 energy. The saturation effect of the silane concentration is not so evident in this case since

299 significant differences in the pullout energy exist between series treated with $0.5 \%$ and with

$300 \quad 1.0 \%$ of TEOS for high $w_{p}$.

301

3024 MICROSTRUCTURAL ANALYSIS

303 Fig. 7 presents the SEM images of the surfaces of the untreated fibre (Fig. 7.a) and of the

304 fibres treated with TEOS at $0.1 \%, 0.5 \%$ and $1.0 \%$ (respectively, Figs. 7 b, c, and d), before they

305 were embedded in the UHPFRC specimens. The atomic compositions determined by EDS at the

306 areas highlighted in each figure are also summarized as percentage concentration of each

307 element, placed above each image. Untreated REF fibres have a smooth surface with small

308 scratches formed during the fabrication process. Conversely, the surfaces of treated fibres

309 reveal the formation of a TEOS film that covers the scratches and create deposits that increase

310 the surface roughness of the fibres. The area covered by the deposits increased with the amount

311 of TEOS used in the functionalization. For instance, fibres treated with $0.1 \%$ of TEOS display only

312 a few small spots, whereas fibres treated with $1.0 \%$ of TEOS have more than $60 \%$ of their surface

313 covered by TEOS deposits. The thickness and uniformity of the film seem to increase with the

314 concentrations of TEOS used. 
316 of the treated fibres. Untreated fibres have mainly $\mathrm{Fe}, \mathrm{Cu}$, and $\mathrm{Zn}$, which is expected in a brass

317 coated steel fibre. No traces of Si or Ca are observed in this case. In contrast, treated fibres

318 present Si and $\mathrm{Ca}$ at their surfaces. The amount of Si at the surface increased as the content of

319 TEOS used for the treatment increased. However, the amount of Ca does not follow the same

trend. Si and Ca were the primary components of the deposits observed in the SEM image.

321

a' Fe=26.99; $\mathrm{Cu}=48.80 ; \mathrm{Zn}=21.21$

a" Fe=33.95; $\mathrm{Cu}=48.21 ; \mathrm{Zn}=17.71$

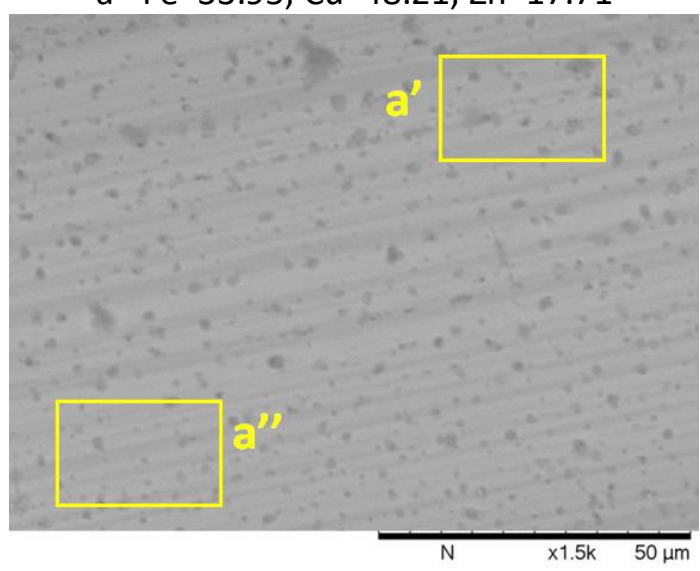

(a)

$\mathrm{Si}=0.95 ; \mathrm{Ca}=11.09 ; \mathrm{Fe}=29.61 ; \mathrm{Cu}=44.30 ; \mathrm{Zn}=14.03$

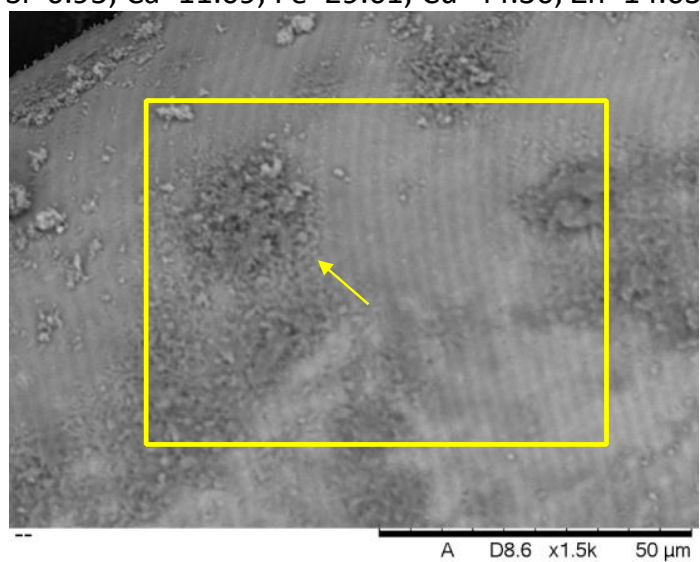

(c)

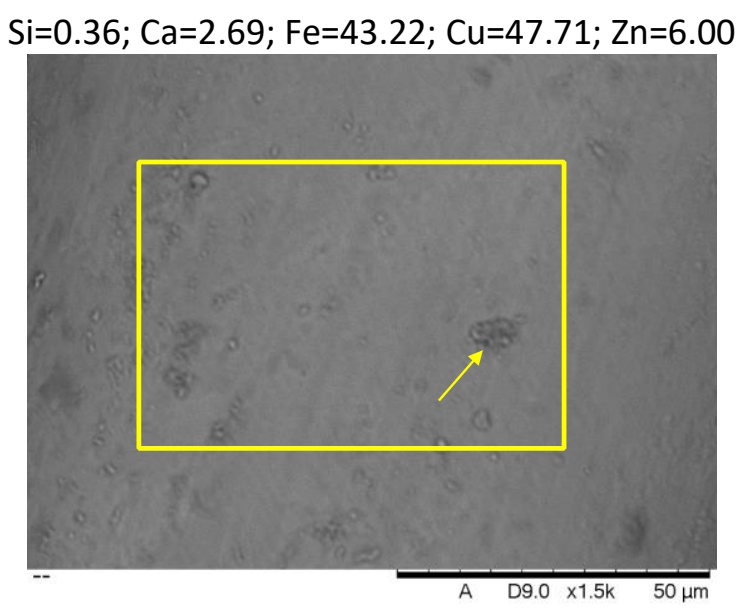

(b)

$\mathrm{Si}=1.15 ; \mathrm{Ca}=6.67 ; \mathrm{Fe}=45.97 ; \mathrm{Cu}=37.83 ; \mathrm{Zn}=8.36$

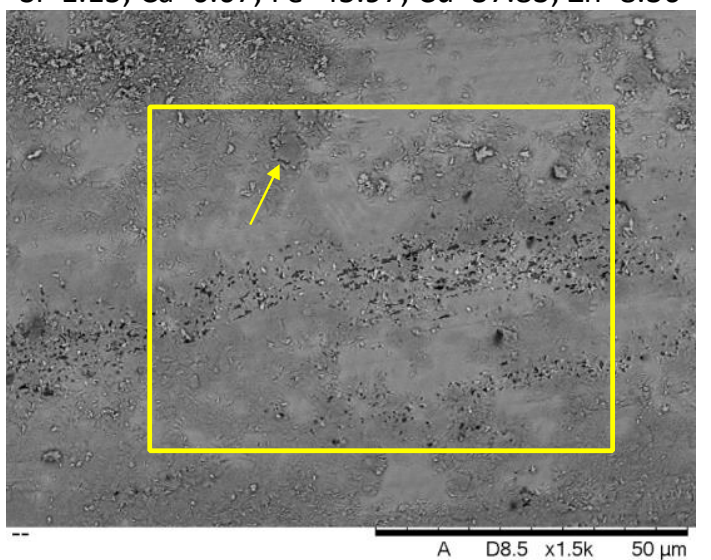

(d)

322 Fig. 7 - SEM images and EDS of fibres before being embedded in the UHPFRC matrix: REF (a),

$3230.1 \%$ (b), $0.5 \%$ (c) and $1.0 \%$ (d). Yellows arrows indicating typical calcium silicate precipitates.

An in-depth analysis of the reactions expected during the fibre treatment might explain 
327 alkoxy groups $\left(\mathrm{Si}-\mathrm{OCH}_{3}\right.$ or $\left.\mathrm{Si}-\mathrm{OC}_{2} \mathrm{H}_{5}\right)$ are converted to hydroxyl groups ( $\left.\mathrm{Si}-\mathrm{OH}\right)$, as described in

328 Eq. 3. Subsequently, Si-OH groups and $\mathrm{OH}^{-}$groups condensate according to Eq. 4 and 5, forming 329 siloxane by covalent bonding [51-53].

330

$$
\begin{aligned}
& \equiv S i-O R+H_{2} \mathrm{O} \leftrightarrow \equiv \mathrm{Si}-\mathrm{OH}+\mathrm{ROH} \\
& \equiv \mathrm{Si}-\mathrm{OR}+\mathrm{HO}-\mathrm{Si} \equiv \leftrightarrow \equiv \mathrm{Si}-\mathrm{O}-\mathrm{Si} \equiv+\mathrm{ROH} \\
& \equiv \mathrm{Si}-\mathrm{OH}+\mathrm{HO}-\mathrm{Si} \equiv \leftrightarrow \equiv \mathrm{Si}-\mathrm{O}-\mathrm{Si} \equiv+\mathrm{H}_{2} \mathrm{O}
\end{aligned}
$$

Where: $\mathrm{R}$ is a radical group (commonly $-\mathrm{CH}_{3}$ or $-\mathrm{C}_{2} \mathrm{H}_{5}$ ).

332

After being activated in the $\mathrm{NaOH}$ bath, Metal-OH (Me-OH) groups are formed at the surface of the fibres. When these fibres are added into the silane bath, the Me-OH groups react with the hydrolysed silane (eq. 6), forming siloxane chains (eq.7) that are deposited on the surface of the fibres. With the heat treatment, neighbouring silane groups undergo a polycondensation process (eq. 8), forming a film on top of the fibre surface. Then, when the $\mathrm{Ca}(\mathrm{OH})_{2}$ bath is performed, the silane hydroxyls in the silane film react with the calcium hydroxide (eq. 9) to form calcium silicates over the fibres.

340

$$
\begin{aligned}
& \mathrm{Si}\left(\mathrm{OC}_{2} \mathrm{H}_{5}\right)_{4}+4 \mathrm{H}_{2} \mathrm{O} \leftrightarrow \mathrm{Si}(\mathrm{OH})_{4}+4 \mathrm{C}_{2} \mathrm{H}_{6} \mathrm{O} \\
& \mathrm{Si}(\mathrm{OH})_{4}+\mathrm{MeOH} \leftrightarrow \mathrm{MeOSi}(\mathrm{OH})_{3}+\mathrm{H}_{2} \mathrm{O} \\
& \mathrm{MeOSi}(\mathrm{OH})_{3}+\mathrm{Si}(\mathrm{OH})_{4} \leftrightarrow \mathrm{MeO}_{2} \mathrm{Si}_{2}(\mathrm{OH})_{5}+\mathrm{H}_{2} \mathrm{O} \\
& \mathrm{MeOSi}(\mathrm{OH})_{3}+\mathrm{Ca}(\mathrm{OH})_{2} \leftrightarrow \mathrm{MeO}_{2} \mathrm{SiCa}(\mathrm{OH})_{3}+\mathrm{H}_{2} \mathrm{O}
\end{aligned}
$$

Where: $\mathrm{R}=-\mathrm{C}_{2} \mathrm{H}_{5}$ or $-\mathrm{CH}_{3}$ and $M e$ is the substrate metal oxide 
345 developed during the functionalization process [33]. Solutions with higher concentration of

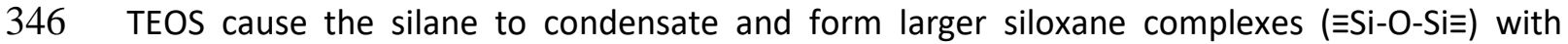

347 neighbouring silanol groups of different lengths. Such molecules may react with the fibre

348 surface, producing a dissimilar thickness of the film on the surface. Another possible explanation

349 relates to heterogeneities in the fibre surface composition. Studies conducted by [33] show that

350 trivalent elements such as $\mathrm{Fe}^{3+}$ have a greater possibility of forming crosslinks with hydrolysed

351 silane if compared with surfaces with divalent elements such as $\mathrm{Zn}^{2+}$. Although the concentration

352 of $\mathrm{Cu}^{2+}$ is similar in the two regions analysed in Fig. 7.a, the concentration of $\mathrm{Fe}^{3+}$ and $\mathrm{Zn}^{2+}$ vary

353 from $26 \%$ to $36 \%$. This may lead to different silane condensation rates and, consequently, the

354 formation of a film with irregular thicknesses over the surface of the fibres.

355 The silane deposits increase the overall surface in contact with the cementitious matrix

356 and induce more tangential load. Furthermore, deposits might act as anchoring sites that

357 generate inclined forces and affect the damage formation during the pullout. These phenomena

358 may be the physical causes for the enhanced pullout response observed in treated fibres.

359 Fig. 8 presents the morphology of the fibres after the pullout test and the EDS results of

360 the amplified areas. REF fibres (Fig. 8.a) show a smooth surface in which the scratches are more

361 visible than before the pullout test, which may be a result of the friction between fibre and the

362 matrix during the sliding stage of the pullout. A small layer of precipitates is found the surface

363 of REF fibres. The EDS results reveal the presence of Si and Ca, suggesting that the layer is

364 possibly generated by the formation of cement hydration products over the surface.

365 In fibres treated with $0.1 \%$ of TEOS (Fig. 8.b), the scratches are less visible than in REF

366 fibres. Moreover, a thicker layer of products remains after the pullout test, although no big

367 deposits are observed. The EDS reveals a higher concentration of Si and Ca than in REF fibres. In

368 fibres treated with $0.5 \%$ of TEOS (Fig. 8.C), not only does a layer of hydration products remain

369 over the fibre surface after the pullout test, but also deposits are clearly observed. The

370 concentration of Si and $\mathrm{Ca}$ is also slightly bigger than the obtained for the sample treated with 
$3710.1 \%$ of TEOS. Similar results are obtained for fibres treated with $1.0 \%$ of TEOS, with a bigger

372 formation of deposits and a bigger concentration of Si and Ca. In fact, portions of the matrix are

373 observed around the fibre after the pullout test. This confirms that the deposits formed at the

374 surface of the fibre during the treatment enhance the mechanical response, possibly working as

375 anchorage sites that increases the contact between the fibre and the matrix.

376 The comparison of the atomic composition assessed before and after the pullout test for

377 the series show that Si increases from $1 \%$ to up to $23 \%$, whereas Ca increases from $11 \%$ to $19 \%$.

378 The increase in Si/Ca ratio suggests a densification in the layer originally formed by the

379 treatment over the fibre due to precipitation of the hydration products. Thus, in addition to the

380 physical anchorage effect previously described, a chemical effect could also be responsible for

381 the enhanced pullout performance of the fibres treated with TEOS. The chemical affinity

382 between the silane layer and the formation of hydration products could favour a densification

383 of the interfacial transition zone, leading to a stronger fibre-matrix bond.

$384 \quad$ Although the assessment of durability falls outside the scope of this work, detailed visual

385 inspection of UHPFRC specimens with functionalized and reference fibres showed no evidence

386 of durability problems after the experimental program. Further studies are required to analyse

387 the stability of the functionalization layer and its interaction with the cementitious matrix over

388 a more extended period.

389

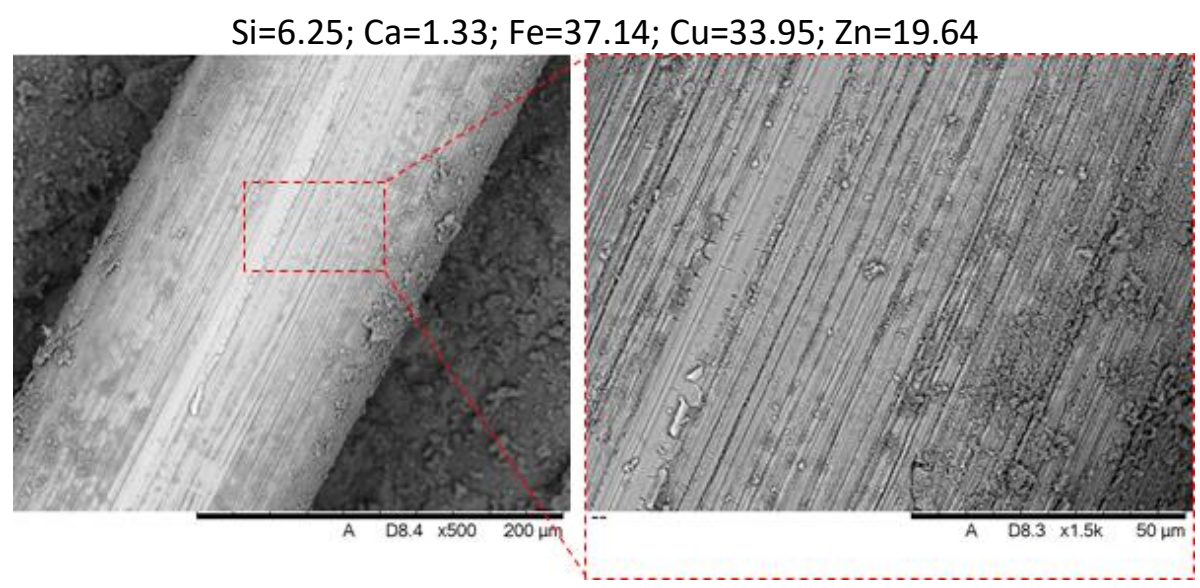

(a) 


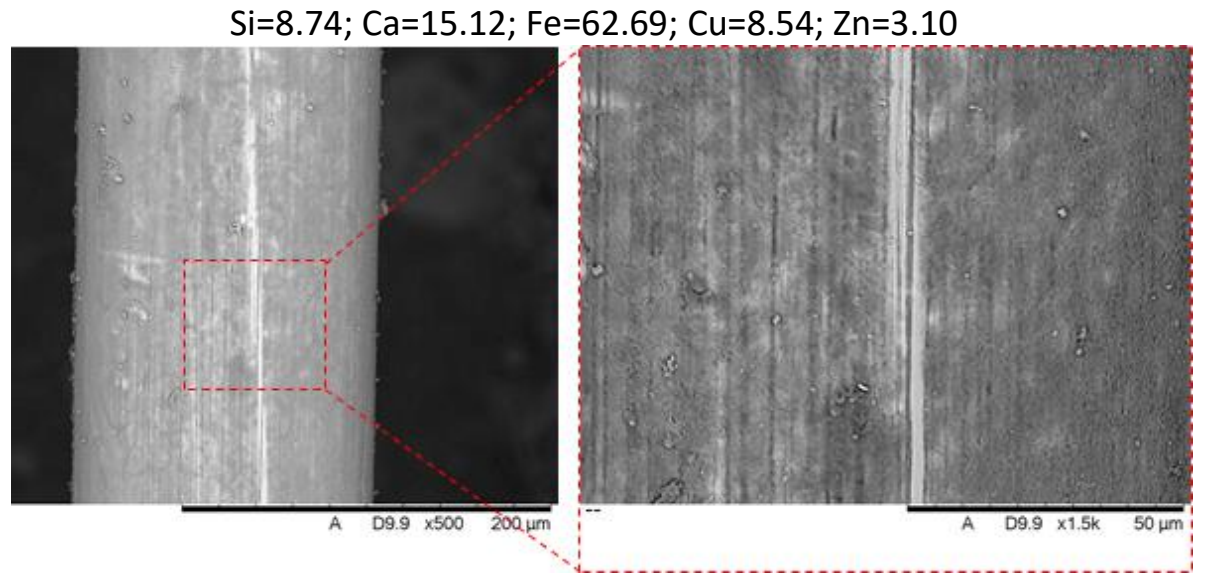

(b)

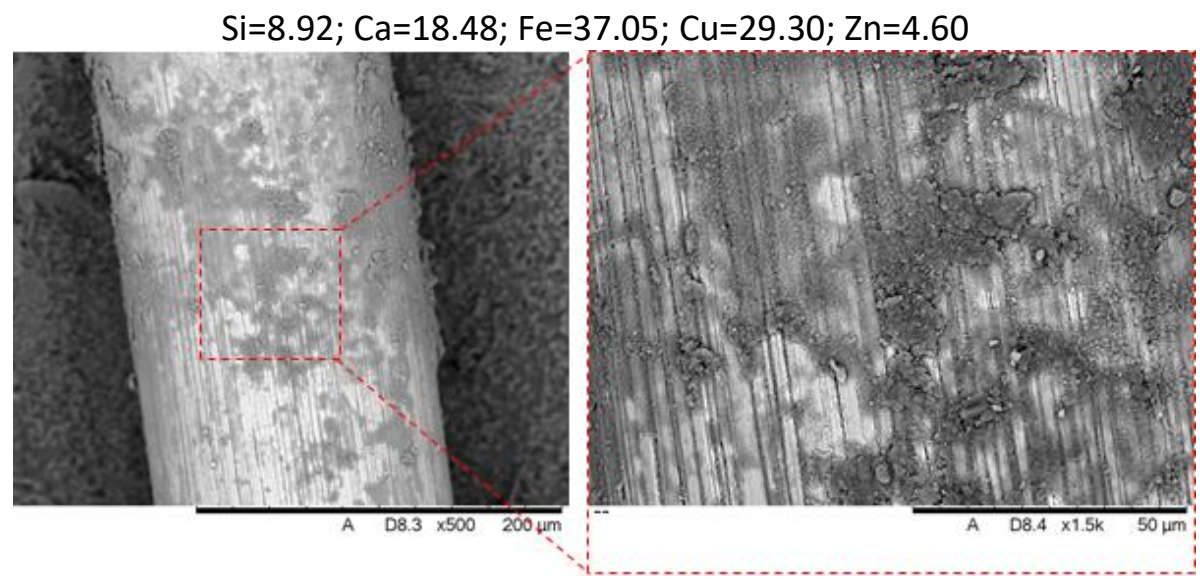

(c)

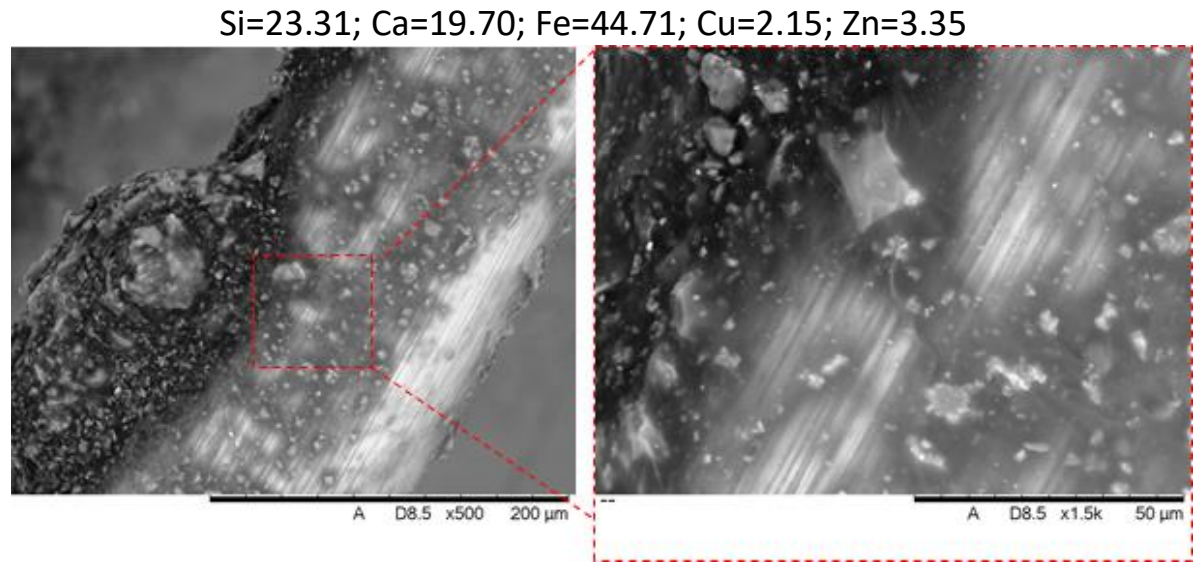

(d)

Fig. 8 - SEM images and EDS of fibres after the pullout test: REF (a), 0.1\% (b), $0.5 \%$ (c) and $1.0 \%$ of TEOS (d)

For a more in-depth analysis of the positive effects of the TEOS layer in the fibre-matrix

394 interfacial transition zone, untreated specimens were sliced with a precision saw and the 
396 conducted to obtain a profile of composition in relation to the distance from the fibre (see Fig.

3979 and Fig. 10). The regions analysed with EDS are indicated by a yellow dot and the line scanning 398 are indicated with a blue line in the corresponding images.

399 The Si/Ca ratio may be used to indirectly assess the composition of the cementitious 400 matrix [56, 57]. Ratios below 0.3 are characteristic of systems with a high proportion of $\mathrm{CH}$, while 401 ratios bigger than 0.3 indicate systems rich in C-S-H [54]. Studies conducted in systems formed 402 mainly by $\mathrm{C}-\mathrm{S}-\mathrm{H}$, without $\mathrm{CH}$, indicate a Si/Ca ratio higher than 0.66 [55].

403 The fibre-matrix interface is dense and homogeneous, with low porosity in all analysed 404 samples, as depicted in Fig. 9.a. REF fibres (Fig. 9.b) present Si/Ca ratios of 0.2 near the fibre. 405 The ratio increases gradually with the distance from the fibre, reaching values consistently above 4060.3 at distances bigger than $4 \mu \mathrm{m}$. This suggests a preferential $\mathrm{CH}$ precipitation around the fibre. 

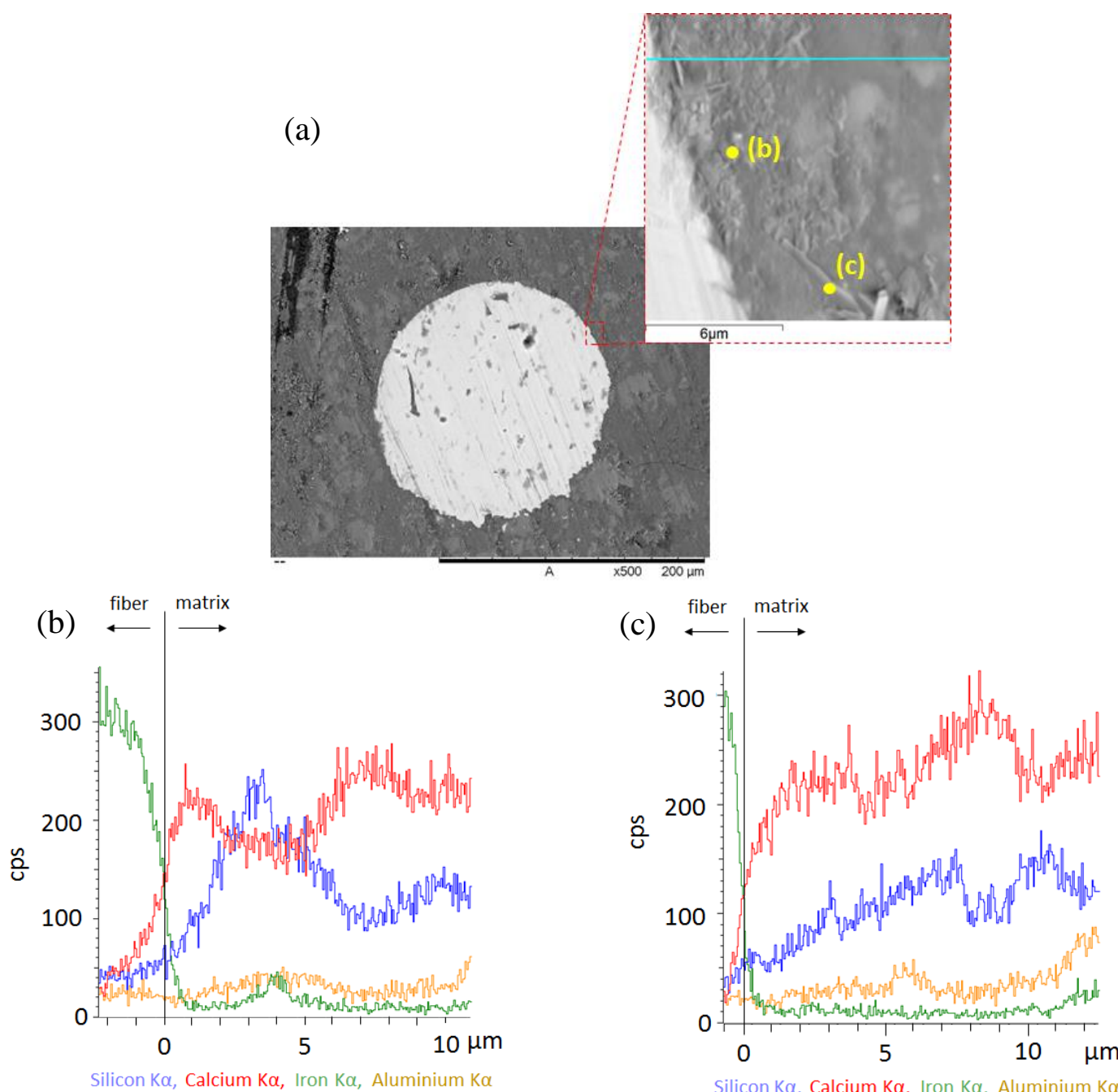

Silicon $\mathrm{K} \alpha$, Calcium $\mathrm{K} \alpha$, Iron $\mathrm{K} \alpha$, Aluminium $\mathrm{K} \alpha$
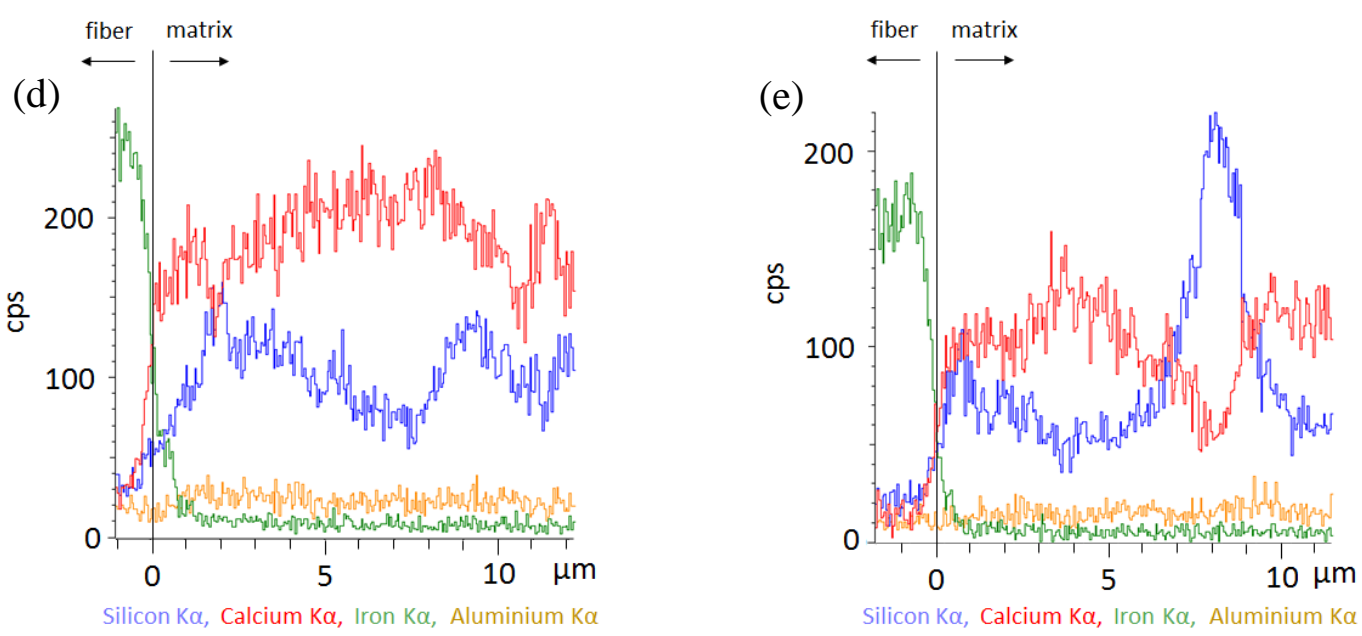
(b), with $0.1 \%$ (c), with $0.5 \%$ (d) and with $1.0 \%$ of TEOS (e). 
413 increase in the $\mathrm{Si} / \mathrm{Ca}$ in points around the fibre, with values bigger than 0.3 . In fact, the Si/Ca

414 reaches 0.3 at a distance of approximately $2 \mu \mathrm{m}$ from the fibre, in contrast with the $4 \mu \mathrm{m}$ found

415 for the untreated fibre. This suggests a higher concentration of C-S-H closer to the surface of the

416 fibre treated with TEOS at $0.1 \%$. Analogous results are found for the samples with fibres treated

417 with $0.5 \%$ (Fig. 9.d) and with $1.0 \%$ (Fig. 9.e) of TEOS. However, in these cases, the Si/Ca ratio of

4180.3 is reached at distances even smaller than $1 \mu \mathrm{m}$ from the fibres. Consequently, the concentration of C-S-H might be higher around the fibres treated with $0.5 \%$ and $1.0 \%$ than both the untreated fibres and the fibres treated with $0.1 \%$ of TEOS.

fibres but not in REF series. This peak is closer to the fibre surface as the content of TEOS in the fibre surface (Fig. 10). This suggests a higher level of densification of the interfacial transition zone due to the fibre treatment proposed in this study, confirming the positive chemical interaction caused by the silane film with cement paste.

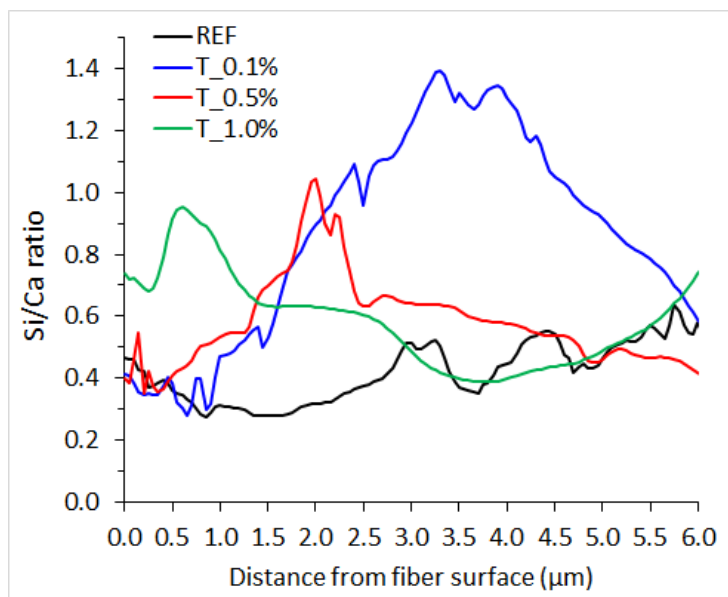

Fig. 10 - Si/ Ca ratio in the transition zone based on EDS line scanning from UHPFRC cross 


\section{CONCEPTUAL MODEL FOR THE FIBRE-MATRIX INTERFACE}

Based on the results obtained in this study, a conceptual model of the evolution of fibrematrix interface is proposed to describe the effect of the functionalization with TEOS adapted from the work by [56]. Fig. 11 depicts the evolution of the hydration of the cement paste and its interaction with the fibre functionalized with TEOS. When the treated fibres come in contact with the cement matrix, the matrix rich in ions $\left(\mathrm{Ca}^{2+}, \mathrm{Si}^{4+}\right.$, and $\left.\mathrm{OH}^{-}\right)$reacts with the silane film forming a diffuse layer. This diffuse layer marks a transition between the silane layer and the cement matrix, as shown in Fig. 11.a.

Over time, the alkaline environment around the fibre solubilizes the TEOS film into $\mathrm{Si}^{4+}$ and $\mathrm{OH}^{-}$that reacts with calcium and leads to $\mathrm{C}-\mathrm{S}-\mathrm{H}$ precipitation. This process may consume part of the silane film, increasing the thickness of the diffuse layer, as shown in Fig. 11.b. The C$\mathrm{S}-\mathrm{H}$ precipitation reduces the $\mathrm{Ca}^{2+}$ availability in the solution around the fibres to form $\mathrm{CH}$. When the $\mathrm{Si} / \mathrm{Ca}$ ratio is around 0.6 , the calcium concentration in the pore solution becomes insufficient to react with the silane film. The increase in C-S-H concentration near the fibre surface could contribute to the densification of the fibre-matrix interface in comparison to the expected in the case of an equivalent non-functionalized fibre.

Differences in the characteristics of these layers may determine how the failure will occur during the pullout test. In case of no functionalization, a low-quality Me-O-Si structure is formed so that the failure may occur at the fibre-silane layer interface or even in the silane layer. The surface of the fibre after the pullout from the matrix should present a morphology similar to that found in untreated fibres. $\mathrm{Si}$ is available to form and densify the diffuse layer. Consequently, a weak diffuse layer is formed, increasing the likelihood of failure along this faulty layer. Slightly higher pullout loads than those obtained in untreated fibres should be expected. After being pulled out from the matrix, fibres 
459 should present a surface covered by a thin layer of silane. This explains the mode of failure

460 observed for the fibres treated with $0.1 \%$ of TEOS.

461 In case of proper functionalization with high enough silane content, a good quality diffuse

462 layer is formed. The failure is likely to occur in the cement matrix, leading to bigger surfaces of

463 failure and, hence, bigger pullout loads. Parts of the cementitious matrix remain attached to the

464 surface of the fibre after the he pullout test. This failure mode was observed in fibres treated

465 with $0.5 \%$ of TEOS and, more evidently, with $1.0 \%$ of TEOS.

466

467

468

469

470

471

472

473

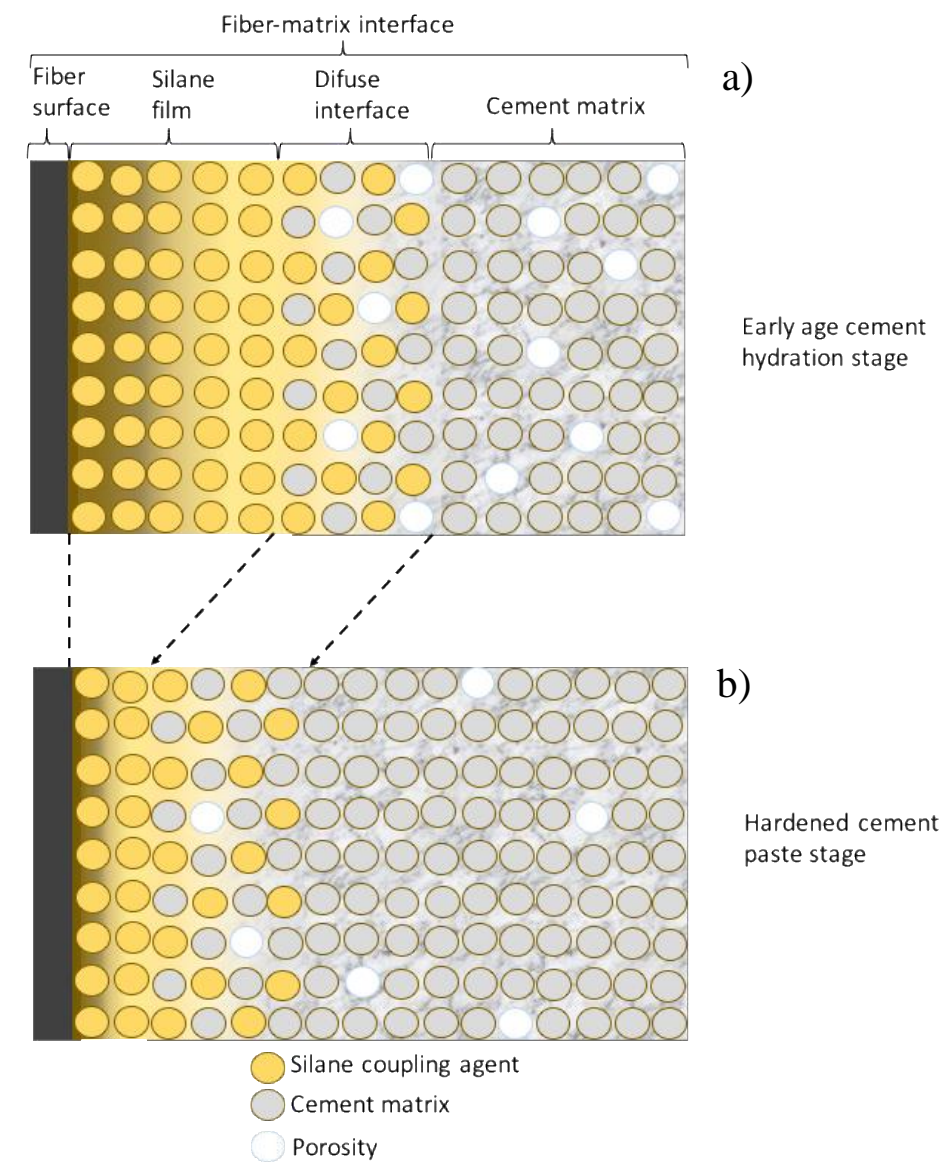

Fig. 11 - Conceptual model of functionalized fibre-matrix interface at short (a) and long term (b). Adapted from [56] 


\section{CONCLUSIONS}

475 Brass coated steel microfibres were functionalized with TEOS and incorporated in a UHPC

476 matrix. The following conclusions resulted from this study:

478 - The bond strength measured in the pullout test increase by up to $35.6 \%$ in fibres subjected

479 to treatment with TEOS. The energy absorbed for crack openings of $0.5 \mathrm{~mm}$ and $2.5 \mathrm{~mm}$

480 were also enhanced for the treated fibres, reaching values up to $36.2 \%$ and $21.9 \%$ bigger

481 than those of the untreated fibres. Analyses confirm that such differences are statistically

$482 \quad$ significant.

483 - An optimal content of TEOS should be used to achieve noticeable improvement in the

484 mechanical performance. In this experimental program, a concentration of $0.1 \%$ did not

485 produce significant improvements in terms of bond strength and pullout energy in 486 comparison with reference untreated fibres.

487 - A saturation in the improvement provided by increasing the content of TEOS is also

488 observed. For example, treatments performed with $0.5 \%$ and with $1.0 \%$ of TEOS lead to 489 almost the same results in terms of bond strength and pullout energy at crack openings 490 of $0.5 \mathrm{~mm}$. Therefore, one of the parameters to be defined in industrial applications is the $491 \quad$ optimum content of TEOS.

492 - Evaluations of the morphology and the composition of the fibre-matrix interface reveal 493 that the improvement in performance generated by the treatment relates to physical and 494 chemical changes. The treatment with TEOS increases the roughness of the fibre surface, 495 increasing the total area of contact and, as a result, the pullout force. In fibres treated 496 with a high content of TEOS, silane deposits are formed over the surface of the fibre. 497 These deposits act as mechanical anchorages that generate inclined forces and increase 498 the surface mobilized during the pullout test. 
- Results also confirm that a chemical interaction between the silane layer and the cement

500 matrix might also contribute to improve the pullout mechanical performance. The matrix

501 rich in ions $\left(\mathrm{Ca}^{2+}, \mathrm{Si}^{4+}\right.$, and $\left.\mathrm{OH}^{-}\right)$react with the silane film forming a diffuse layer. The

502 alkaline environment around the fibre solubilizes the TEOS film into $\mathrm{Si}^{4+}$ and $\mathrm{OH}^{-}$that react

503 with calcium, producing C-S-H in the interface transition zone. EDS measurements reveal

504 that treated fibres show Si/Ca ratios several times higher than untreated fibres,

505 suggesting the additional presence of C-S-H that justifies a stronger interface transition

$506 \quad$ zone.

507 - A heterogeneity in terms of thickness and area covered by the silane film was observed in

508 the surface of fibres treated with $0.5 \%$ and $1.0 \%$ of TEOS. This heterogeneity may be

509 attributed to the high concentration of TEOS that tend to condensate and form larger

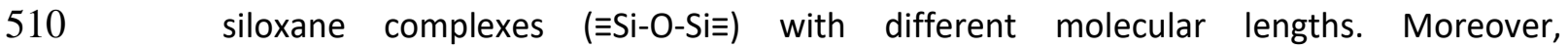

511 heterogeneities in the fibre surface composition may favour different silane condensation

512 rates and, consequently, film thicknesses over the fibre's surface.

513 - The failure mode observed in the pullout test is affected by the treatment applied.

514 Untreated fibres fail in the fibre-matrix interface due to the weaker interface generated.

$515 \quad$ Fibres treated with $0.1 \%$ of TEOS do not present enough silane to form a strong diffuse

516 layer around the fibres. Consequently, the failure occurs in the diffuse zone so that a

517 remaining silane layer is observed around the fibre after the pullout test. In contrast,

518 fibres treated with $0.5 \%$ and $1.0 \%$ of TEOS present a diffuse zone with high concentration

519 of C-S-H and silane deposits that promote a failure through the cement matrix. The

520 inspection of the fibres after the pullout test show the presence of cracked chunks of the

521 matrix around the fibre, confirming the stronger interface transition zone and the need

522 to mobilize a bigger surface during failure. This is the cause of the increment in the pullout

$523 \quad$ load and energy observed. 


\section{ACKNOWLEDGMENTS}

The authors thank Coordenação de Aperfeiçoamento de Pessoal de Nível Superior (CAPES) by the international scholarship in the project 99999.000243/2015-09, to the Universidad Politècnica de Catalunya (UPC) for providing part of the infrastructure for the research, to the Programa de Pós-graduação em Engenharia Civil (PPGEC) for the fully funded scholarship, to NANOTEC and CERMAT through the LINDEN/UFSC for the technical support in the microstructural investigation, and to Ms. Maria Helena and Dr. Lidiane F. Jochem for their support in the experimental program.

\section{REFERENCES}

[1] H.. Bache, Densified cement ultrafine particle-based materials, in: 2nd Int. Conf. Superplast. Concr., Otawa, 1981: p. 33.

[2] J.D. Birchall, A.J. Howard, K. Kendall, Flexural strength and porosity of cements, Nature. 289 (1981) 388-390. doi:10.1038/289388a0.

[3] A.E. Naaman, K. Wille, The path to Ultra-High Performance Fiber Reinforced Concrete (UHP-FRC): Five decades of progress, in: M. Schimidt, E. Fehling, C. Glotzbach, S. Fröhlich, P. S (Eds.), Proc. Hipermat 2012 - 3rd Int. Symp. UHPC Nanotechnol. High Perform. Constr. Mater., Kassel University Press, 2012: pp. 3-16.

[4] H. Russel, G, B.A. Graybeal, Ultra-High Performance Concrete: A State-of-the-Art Report for the Bridge Community - Publication N ${ }^{\circ}$ FHWA-HRT-13-060, McLean, 2013. https://www.fhwa.dot.gov/publications/research/infrastructure/structures/hpc/13060 /.

[5] K. Kono, H. Musha, T. Kawaguchi, A. Eriguchi, S. Tanaka, T. Kobayashi, M. Ikeda, Durability study of the first PC bridge constructed with ultra high strength fiber reinforced concrete in japan, in: RILEM-Fib-AFGC Int. Symp. Ultra-High Perform. FibreReinforced Concr. UHPFRC 2013, RILEM Publications SARL, Marseille, France, 2013: pp. $239-248$. http://www.rilem.org/gene/main.php?base=500218\&id_publication=422\&id_papier=8 865 (accessed August 11, 2014).

[6] D.-Y. Yoo, J.-H. Lee, Y.-S. Yoon, Effect of fiber content on mechanical and fracture properties of ultra high performance fiber reinforced cementitious composites, Compos. Struct. 106 (2013) 742-753. doi:10.1016/j.compstruct.2013.07.033.

[7] C. Shi, Z. Wu, J. Xiao, D. Wang, Z. Huang, Z. Fang, A review on ultra high performance concrete: Part I. Raw materials and mixture design, Constr. Build. Mater. 101 (2015) 741-751. doi:10.1016/j.conbuildmat.2015.10.088.

[8] C. Difrancia, T.C. Ward, R.O. Claus, The single-fibre pull-out test. 1: Review and interpretation, Compos. Part A Appl. Sci. Manuf. 27 (1996) 597-612. doi:10.1016/1359835X(95)00069-E.

[9] J.M. Alwan, A.E. Naaman, W. Hansen, Pull-out work of steel fibers from cementitious composites: Analytical investigation, Cem. Concr. Compos. 13 (1991) 247-255. doi:10.1016/0958-9465(91)90030-L.

[10] Y.-W. Chan, S.-H. Chu, Effect of silica fume on steel fiber bond characteristics in reactive powder concrete, Cem. Concr. Res. 34 (2004) 1167-1172. doi:10.1016/j.cemconres.2003.12.023. 
[11] K. Wille, A.E. Naaman, S. El-Tawil, G.J. Parra-Montesinos, Ultra-high performance concrete and fiber reinforced concrete: achieving strength and ductility without heat curing, Mater. Struct. 45 (2011) 309-324. doi:10.1617/s11527-011-9767-0.

[12] R. Yu, P. Spiesz, H.J.H. Brouwers, Effect of nano-silica on the hydration and microstructure development of Ultra-High Performance Concrete (UHPC) with a low binder amount, Constr. Build. Mater. 65 (2014) 140-150. doi:10.1016/j.conbuildmat.2014.04.063.

[13] S.-T. Kang, J.-K. Kim, Investigation on the flexural behavior of UHPCC considering the effect of fiber orientation distribution, Constr. Build. Mater. 28 (2012) 57-65. doi:10.1016/j.conbuildmat.2011.07.003.

[14] J. Liu, F. Han, G. Cui, Q. Zhang, J. Lv, L. Zhang, Z. Yang, Combined effect of coarse aggregate and fiber on tensile behavior of ultra-high performance concrete, Constr. Build. Mater. 121 (2016) 310-318. doi:10.1016/j.conbuildmat.2016.05.039.

[15] T. Sugama, N. Carciello, L.E. Kukacka, G. Gray, Interface between zinc phosphatedeposited steel fibres and cement paste, J. Mater. Sci. 27 (1992) 2863-2872. doi:10.1007/BF01154093.

[16] P. Frantzis, R. Baggott, Bond between reinforcing steel fibres and magnesium phosphate/calcium aluminate binders, Cem. Concr. Compos. 22 (2000) 187-192. doi:10.1016/S0958-9465(00)00006-8.

[17] D.V. Soulioti, N.-M. Barkoula, F. Koutsianopoulos, N. Charalambakis, T.E. Matikas, The effect of fibre chemical treatment on the steel fibre/cementitious matrix interface, Constr. Build. Mater. 40 (2013) 77-83. doi:10.1016/j.conbuildmat.2012.09.111.

[18] D.G. Aggelis, D.V. Soulioti, E.A. Gatselou, N.-M. Barkoula, T.E. Matikas, Monitoring of the mechanical behavior of concrete with chemically treated steel fibers by acoustic emission, Constr. Build. Mater. 48 (2013) 1255-1260. doi:10.1016/j.conbuildmat.2012.06.066.

[19] E.P. Plueddemann, Silane Coupling Agents, Second, Springer US, Boston, MA, 1991. doi:10.1007/978-1-4899-2070-6.

[20] J. Minet, S. Abramson, B. Bresson, C. Sanchez, V. Montouillout, N. Lequeux, New Layered Calcium Organosilicate Hybrids with Covalently Linked Organic Functionalities, Chem. Mater. 16 (2004) 3955-3962. doi:10.1021/cm034967o.

[21] J. Minet, S. Abramson, B. Bresson, A. Franceschini, H. Van Damme, N. Lequeux, Organic calcium silicate hydrate hybrids: a new approach to cement based nanocomposites, J. Mater. Chem. 16 (2006) 1379. doi:10.1039/b515947d.

[22] A. Franceschini, S. Abramson, V. Mancini, B. Bresson, C. Chassenieux, N. Lequeux, New covalent bonded polymer?calcium silicate hydrate composites, J. Mater. Chem. 17 (2007) 913. doi:10.1039/b613077a.

[23] X.-M. Kong, H. Liu, Z.-B. Lu, D.-M. Wang, The influence of silanes on hydration and strength development of cementitious systems, Cem. Concr. Res. 67 (2015) 168-178. doi:10.1016/j.cemconres.2014.10.008.

[24] J. Cao, D.D.L. Chung, Improving the dispersion of steel fibers in cement mortar by the addition of silane, Cem. Concr. Res. 31 (2001) 309-311. doi:10.1016/S00088846(00)00470-1.

[25] G. Collodetti, P.J.P. Gleize, P.J.M. Monteiro, Exploring the potential of siloxane surface modified nano-SiO2 to improve the Portland cement pastes hydration properties, Constr. Build. Mater. 54 (2014) 99-105. doi:10.1016/j.conbuildmat.2013.12.028.

[26] H. Herb, A. Gerdes, G. Brenner-Weiß, Characterization of silane-based hydrophobic admixtures in concrete using TOF-MS, Cem. Concr. Res. 70 (2015) 77-82. doi:10.1016/j.cemconres.2015.01.008.

[27] B. Felekoğlu, A method for improving the early strength of pumice concrete blocks by using alkyl alkoxy silane (AAS), Constr. Build. Mater. 28 (2012) 305-310. doi:10.1016/j.conbuildmat.2011.07.026. 
620 [28] W. Fan, F. Stoffelbach, J. Rieger, L. Regnaud, A. Vichot, B. Bresson, N. Lequeux, A new

621

622

623

624

625

626

627

628

629

630

631

632

633

634

635

636

637

638

639

640

641

642

643

644

645

646

647

648

649

650

651

652

653

654

655

656

657

658

659

660

661

662

663

664

665

666

667

668

669

670

671 class of organosilane-modified polycarboxylate superplasticizers with low sulfate sensitivity, Cem. Concr. Res. 42 (2012) 166-172. doi:10.1016/j.cemconres.2011.09.006.

[29] M. Benzerzour, N. Sebaibi, N.E. Abriak, C. Binetruy, Waste fibre-cement matrix bond characteristics improved by using silane-treated fibres, Constr. Build. Mater. 37 (2012) 1-6. doi:10.1016/j.conbuildmat.2012.07.024.

[30] N. Sebaibi, M. Benzerzour, N.E. Abriak, C. Binetruy, Mechanical properties of concretereinforced fibres and powders with crushed thermoset composites: The influence of fibre/matrix interaction, Constr. Build. Mater. 29 (2012) 332-338.

doi:10.1016/j.conbuildmat.2011.10.026.

[31] Z. Yang, J. Liu, J. Liu, C. Li, H. Zhou, Silica modified synthetic fiber for improving interface property in FRCC, in: J.A.O. Barros (Ed.), 8th RILEM Int. Symp. Fibre Reinf. Concr. Challenges Oppor. (BEFIB 2012), RILEM Publications SARL, 2012: pp. 347-357. http://www.rilem.org/gene/main.php?base $=500218 \& i d \_p u b l i c a t i o n=419 \& i d \_p a p i e r=8$ 647.

[32] L. Téllez, F. Rubio, R. Peña-Alonso, J. Rubio, Seguimiento por espectroscopia infrarroja (FT-IR) de la copolimerización de TEOS (tetraetilortosilicato) y PDMS (polidimetilsiloxano) en presencia de tbt (tetrabutiltitanio), Bol. La Soc. Esp. Ceram. y Vidr. 43 (2004) 883-890. doi:10.3989 /cyv.2004.v43.i5.

[33] W.J. Van Ooij, D. Zhu, M. Stacy, A. Seth, T. Mugada, J. Gandhi, P. Puomi, Corrosion Protection Properties of Organofunctional Silanes - An Overview, Tsinghua Sci. Technol. 10 (2005) 639-664.

[34] P.H. Suegama, I. V Aoki, Electrochemical behavior of carbon steel pre-treated with an organo functional bis-silane filled with copper phthalocyanine, J. Braz. Chem. Soc. 19 (2008) 744-754. doi:10.1590/S0103-50532008000400019.

[35] M.R. Bagherzadeh, A. Daneshvar, H. Shariatpanahi, Novel water-based nanosiloxane epoxy coating for corrosion protection of carbon steel, Surf. Coatings Technol. 206 (2012) 2057-2063. doi:10.1016/j.surfcoat.2011.05.036.

[36] W. Yuan, van Ooij WJ, Characterization of Organofunctional Silane Films on Zinc Substrates, J. Colloid Interface Sci. 185 (1997) 197-209. http://www.ncbi.nlm.nih.gov/pubmed/9056330.

[37] A.V. Cunliffe, S. Evans, D.A. Tod, S.A. Torry, P. Wylie, Optimum preparation of silanes for steel pre-treatment, Int. J. Adhes. Adhes. 21 (2001) 287-296. doi:10.1016/S01437496(01)00004-5.

[38] R. Yu, P. Spiesz, H.J.H.J.H. Brouwers, Development of an eco-friendly Ultra-High Performance Concrete (UHPC) with efficient cement and mineral admixtures uses, Cem. Concr. Compos. 55 (2015) 383-394. doi:10.1016/j.cemconcomp.2014.09.024.

[39] K. Koh, G.S. Ryu, J. Park, K.H. An, S.W. Kim, Effects of the composing materials on the rheological and mechanical properties of ultra-high performance concrete (UHPC), in: F. Toutlemonde, J. Resplendino (Eds.), RILEM-Fib-AFGC Int. Symp. Ultra-High Perform. Fibre-Reinforced Concr. UHPFRC 2013, RILEM Publications SARL, Marseille, France, 2013: pp. 749-756.

[40] D.J. Kim, S.H. Park, G.S. Ryu, K.T. Koh, Comparative flexural behavior of Hybrid Ultra High Performance Fiber Reinforced Concrete with different macro fibers, Constr. Build. Mater. 25 (2011) 4144-4155. doi:10.1016/j.conbuildmat.2011.04.051.

[41] AENOR, Asociación Española de Normalización y Certificación - UNE-EN 197-1 Cemento - Parte1: Composición, especificaciones y criterios de conformidad de los cementos comunes, 2011. http://www.aenor.es/aenor/normas/normas/fichanorma.asp?tipo=N\&codigo=N00486 23\#.VyEWb1bhDDd.

[42] ASTM, C1437 - Standard test method for flow of hydraulic cement mortar, 2013.

[43] AENOR, UNE-EN 196-1. Métodos de ensayo de cementos - Parte 1: Determinación de 
672

673

674

675

676

677

678

679

680

681

682

683

684

685

686

687

688

689

690

691

692

693

694

695

696

697

698

699

700

701

702

703

704

705

706

707

708

resistencias mecánicas, (2005) 35.

[44] Y. Lee, S.-T. Kang, J.-K. Kim, Pullout behavior of inclined steel fiber in an ultra-high strength cementitious matrix, Constr. Build. Mater. 24 (2010) 2030-2041. doi:10.1016/j.conbuildmat.2010.03.009.

[45] J.-P. Won, B.-T. Hong, S.-J. Lee, S.J. Choi, Bonding properties of amorphous micro-steel fibre-reinforced cementitious composites, Compos. Struct. 102 (2013) 101-109. doi:10.1016/j.compstruct.2013.02.015.

[46] Z. Wu, C. Shi, K.H. Khayat, Influence of silica fume content on microstructure development and bond to steel fiber in ultra-high strength cement-based materials (UHSC), Cem. Concr. Compos. 71 (2016) 97-109. doi:10.1016/j.cemconcomp.2016.05.005.

[47] Fedération Internationale du Béton, International Federation for Structural Concrete (fib) Model Code 2010 - First complete draft - Volume 1 - Bulletin 55: march, Lausanne Switzerland, 2010.

[48] S.H. Kang, T.-H. Ahn, D.J. Kim, Effect of grain size on the mechanical properties and crack formation of HPFRCC containing deformed steel fibers, Cem. Concr. Res. 42 (2012) 710-720. doi:10.1016/j.cemconres.2012.02.011.

[49] S.H. Kang, J.J. Kim, D.J. Kim, Y.-S. Chung, Effect of sand grain size and sand-to-cement ratio on the interfacial bond strength of steel fibers embedded in mortars, Constr. Build. Mater. 47 (2013) 1421-1430. doi:10.1016/j.conbuildmat.2013.06.064.

[50] Z. Wu, K.H. Khayat, C. Shi, Effect of nano-SiO 2 particles and curing time on development of fiber-matrix bond properties and microstructure of ultra-high strength concrete, Cem. Concr. Res. 95 (2017) 247-256. doi:10.1016/j.cemconres.2017.02.031.

[51] C.J. Brinker, Hydrolysis and condensation of silicates: Effects on structure, J. Non. Cryst. Solids. 100 (1988) 31-50. doi:10.1016/0022-3093(88)90005-1.

[52] J.C. Ro, I.J. Chung, Sol-gel kinetics of tetraethylorthosilicate (TEOS) in acid catalyst, J. Non. Cryst. Solids. 110 (1989) 26-32. doi:10.1016/0022-3093(89)90178-6.

[53] Y. Hui, D. Zishang, J. Zhonghua, X. Xiaoping, Sol-gel process kinetics for Si(OEt)4, J. Non. Cryst. Solids. 112 (1989) 449-453. doi:10.1016/0022-3093(89)90571-1.

[54] R.P. Salvador, S.H.P. Cavalaro, I. Segura, A.D. De, Early age hydration of cement pastes with different types of accelerators for sprayed concrete, Constr. Build. Mater. 111 (2016) 1-29. doi:10.1016/j.conbuildmat.2016.02.101.

[55] A. Nonat, The structure and stoichiometry of C-S-H, Cem. Concr. Res. 34 (2004) 15211528. doi:10.1016/j.cemconres.2004.04.035.

[56] T. Materne, F. Buyl, G.L. Witucki, Organosilane Technology in Coating Applications: Review and Perspectives, Dow Corning. (2010) 1-16. 